\title{
Isolate patients, screen staff to fight MRSA
}

Strategies to contain methicillinresistant Staphylococcus aureus will fail unless they include screening all health care workers and decolonizing carriers, say Dutch researchers.

The Netherland's strict "search and destroy" tactics, which include staff screening, have kept its MRSA infection rates lower than in other European countries, including the UK.

In England, more than $40 \%$ of $S$. aureus bloodstream infections are now methicillin resistant, up from $2 \%$ in 1994. This

$\exists$ is one of the highest rates in Eu-

rope, compared with $1 \%$ in The Netherlands.

In Canada, the incidence of MRSA, as a proportion of $S$. aureus isolates, increased from $1 \%$ in 1995 to $8 \%$ in 2000 (CMA7 2002;167[8]:885-91).
In December 2003, Sir Liam Donaldson, England's chief medical officer, issued guidelines for the National Health Service aimed at improving infection control.

But a National Audit Report issued 6 months later called implementation of the government's infection control strategy "patchy."

Efforts to control MRSA in Canada include reducing inappropriate prescribing and reducing transmission through enhanced infection control and environmental hygiene.

Dutch doctors say these strategies alone won't work if they neglect extensive screening.

"Health care workers are one of the main routes of transmission of resistant bacteria, including MRSA," says Heiman Wertheim, a research scientist at
Erasmus University Medical Centre's department of microbiology and infectious diseases in Rotterdam. "So if you forget to screen them and you don't treat the carriers, your MRSA infection control policy will fail."

Professor Andreas Voss of the University Medical Centre St. Radboud, in Nijmegen, adds that infection control strategies will fail unless they include both health care worker screening and decolonization: treating colonized patients with antibiotics to rid them of the infection.

In addition to screening staff, the MRSA "search and destroy" control strategies used in the Netherlands include isolating infected patients and closing wards for extensive cleaning if an outbreak occurs. - Colin Meek, Wester Ross, Scotland

\section{Adverse Events}

\section{Mandatory error reporting in Saskatchewan}

Saskatchewan has become the first jurisdiction in Canada to require health districts to report all medical errors to the province.

The Saskatchewan Department of Health will analyze the details of each reported event and issue province-wide alerts in cases where similar incidents could be prevented.

"We're quite excited about this," says Duncan Fisher, the department's assistant deputy minister. "Mistakes do happen from time to time, no matter how good systems are, and sometimes human error does occur. We want to minimize that as much as possible."

Information released about the error will include details about the incident and corrective steps taken, but will not include the names of the patient or the medical professionals involved.

"This isn't about blaming in- dividuals, this is about patient safety and trying to identify opportunities for system-wide change," says Fisher. "We want people to share information about things that have gone wrong with the hope of preventing them from going wrong again someplace else."

Legislation requiring the health districts to report medical errors took effect in September. Six types of critical incidents must be reported: serious surgical errors; crippling mistakes in medication; patient disappearance or suicide inside a health facility; errors resulting in death or disability to mother or child during labour; and serious injury due to delays in transportation or emergency care.

The legislation also requires health districts to report criminal activities such as impersonation of a doctor, abduction of a patient and incidents of physical or sexual assault.
For the past two years, districts have reported on a voluntary basis. There has been no reluctance to make the reporting mandatory, Fisher says.

In one well-publicized case in the province, a retractor was left inside a patient after surgery. Details of that incident were reported to the Department of Health and resulted in a province-wide alert, Fisher says.

"We're showing that patient safety is important to us, and we have to create more of that culture within the health system," he says.

The College of Physicians and Surgeons of Saskatchewan supports the legislation.

"Patients deserve to receive the safest possible treatment, and, as a physician, I applaud initiatives that promote a culture of safety," said Dr. Dennis Kendel, the college's registrar. - Amy fo Ebman, Saskatoon 